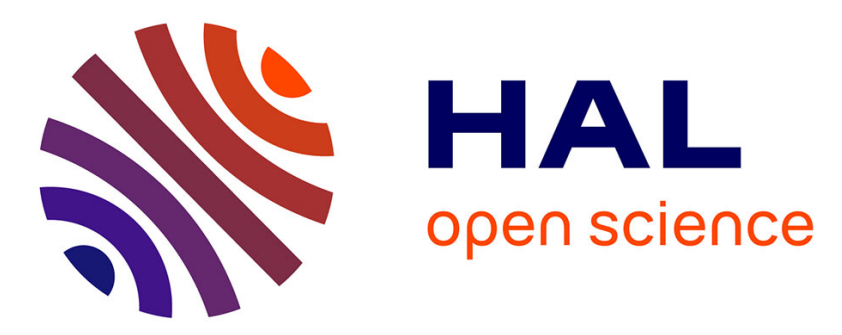

\title{
Formulation and assessment of an enhanced finite element procedure for the analysis of delamination growth phenomena in composite structures
}

Elisa Pietropaoli, Aniello Riccio

\section{- To cite this version:}

Elisa Pietropaoli, Aniello Riccio. Formulation and assessment of an enhanced finite element procedure for the analysis of delamination growth phenomena in composite structures. Composites Science and Technology, 2011, 71 (6), pp.836. 10.1016/j.compscitech.2011.01.026 . hal-00736296

\section{HAL Id: hal-00736296 https://hal.science/hal-00736296}

Submitted on 28 Sep 2012

HAL is a multi-disciplinary open access archive for the deposit and dissemination of scientific research documents, whether they are published or not. The documents may come from teaching and research institutions in France or abroad, or from public or private research centers.
L'archive ouverte pluridisciplinaire HAL, est destinée au dépôt et à la diffusion de documents scientifiques de niveau recherche, publiés ou non, émanant des établissements d'enseignement et de recherche français ou étrangers, des laboratoires publics ou privés. 


\section{Accepted Manuscript}

Formulation and assessment of an enhanced finite element procedure for the analysis of delamination growth phenomena in composite structures

Elisa Pietropaoli, Aniello Riccio

PII:

S0266-3538(11)00054-6

DOI:

10.1016/j.compscitech.2011.01.026

Reference:

CSTE 4921

To appear in:

Composites Science and Technology

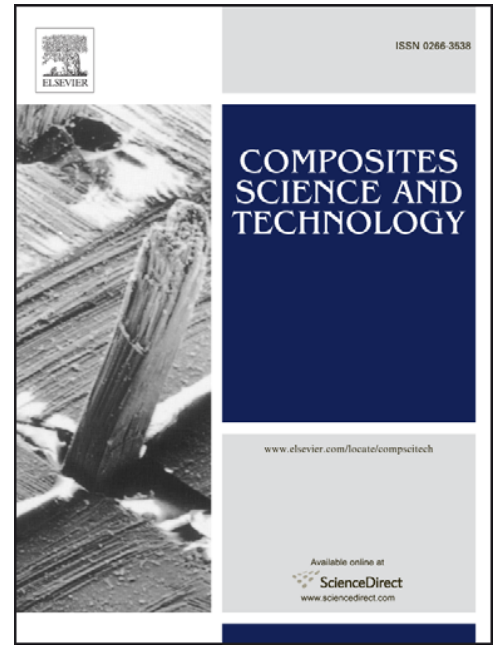

Received Date: $\quad 25$ October 2010

Revised Date: $\quad 21$ January 2011

Accepted Date: $\quad 30$ January 2011

Please cite this article as: Pietropaoli, E., Riccio, A., Formulation and assessment of an enhanced finite element procedure for the analysis of delamination growth phenomena in composite structures, Composites Science and Technology (2011), doi: 10.1016/j.compscitech.2011.01.026

This is a PDF file of an unedited manuscript that has been accepted for publication. As a service to our customers we are providing this early version of the manuscript. The manuscript will undergo copyediting, typesetting, and review of the resulting proof before it is published in its final form. Please note that during the production process errors may be discovered which could affect the content, and all legal disclaimers that apply to the journal pertain. 


\title{
Formulation and assessment of an enhanced finite element procedure for the analysis of delamination growth phenomena in composite structures.
}

\author{
Elisa Pietropaoli* , Aniello Riccio ${ }^{\dagger}$, \\ *CIRA Italian Aerospace Research Center \\ via Maiorise, 81043 Capua, ITALY \\ e.pietropaoli@cira.it $\left(^{*}\right)$,a.riccio@cira.it $\left(^{\dagger}\right)$
}

\begin{abstract}
An existing procedure based on the combined use of the Virtual Crack Closure Technique and of a fail release approach for the analysis of delamination growth phenomena in composite structures has been enhanced with a front-tracing algorithm and suitable expressions for the evaluation of the Strain Energy Release Rate when dealing with non-smoothed delamination fronts. The enhanced procedure has been implemented into a commercial finite element software by means of user subroutines and applied to the analysis of a composite stiffened panel with an embedded delamination under compressive load. The effectiveness and robustness of the enhanced procedure have been assessed by comparing literature experimental data and numerical results obtained by using different mesh densities in the damaged area (global/local approach).
\end{abstract}

\section{KEYWORDS}

A. Layered structures, B. Delamination, C. Buckling, D. Damage mechanics, C. Finite element analysis, C. Global-local

\section{Introduction}

A delamination is a debonding between adjacent layers in composite materials which can be considered as an interlaminar crack and analysed by using fracture mechanics concept. The status of a delamination (at which load level it starts growing, at which rate it propagates) can be studied by evaluating the Strain Energy Release Rate. The wide spread use of the finite element method has promoted the development of numerical techniques for the evaluation of the Strain Energy Release Rate such as the Virtual Crack Closure Technique (VCCT) [1-4]. This technique allows the Strain Energy Release Rate to be computed starting from forces at the crack tip and relative displacements of the crack faces behind it. Even if very simple in its theory, the VCCT is very accurate in evaluating the Strain Energy Release Rate for smoothed delamination fronts (i.e. straight or circular/elliptical 
when modelled by using orthogonal meshes with edges parallel or orthogonal to the delamination front). When the delamination growth is of concern, the VCCT can be used in conjunction with interface elements [5-7] or with a fail release approach [8-10] whose effect is that to simulate the growth process by releasing constraints between crack faces when the Strain Energy Release Rate level overcomes critical values (instantaneous propagation). However, during the propagation the delamination front may assume complex and non-smoothed shapes with corners. Indeed, corners are also present in the delamination front when non-orthogonal meshes are used. The non-smoothness of the delamination front causes difficulties in the application of the VCCT concerning the individuation of the direction normal to the delamination front in a node which is a corner as well as in the determination of the portion of area to be ascribed to that node for the Strain Energy Release Rate computation. Ferrie et al. [11] were one of the first to address this problem. They analysed the Strain Energy Release Rate on a circular crack by using a non orthogonal mesh taking into account the presence of corners and proposed an approach based on the introduction of predetermined weight factors in VCCT formulae. Xie and Biggers [6-7] analysed an analogous problem taking into account also the crack growth phenomenon and proposed an efficient algorithm to trace a moving delamination front on a non-orthogonal mesh. Furthermore, a procedure based on geometrical considerations was defined by Xie and Biggers able to determine areas to be used in VCCT formulae taking into account the real shape of the delamination. Mabson et al. [5] emphasized the tendency for corner nodes to accumulate energy in a Double Cantilever Beam specimen and than to be smoothed thus inducing to a misleading prediction of the shape of the delamination front. Orifici et al [8] analysed the delamination growth in an analogous specimen by using four different approaches and individuating the best correlation between numerical and experimental results in terms of growth rate when weight factors were introduced in VCCT formulae. These weight factors were not predetermined as in Ref.11 but computed taking into account the shape of the local crack front created when constraints are released. The robustness of procedure based on VCCT was investigated by Krueger [12-13] who analysed effects of choice of element types, integration order and analyses parameters (such as release tolerance,damping factors and so on) on delamination growth simulation. Pietropaoli and Riccio [10] 
analysed the robustness of finite element procedures based on Virtual Crack Closure Technique and fail release approach for delamination growth phenomena and discussed their inherently dependence on the load increment and element size in the frame of non linear incremental analyses by means of theoretical considerations. The Authors also proposed a novel finite element procedure named SMART-APPROACH [10], which was able to define an automatic adjustment of the load step size on the basis of the Strain Energy Release Rate computed and of the shape of the delamination at each load level of a non linear incremental analysis. The effectiveness of this procedure was proved on a stiffened panel with an embedded circular delamination subjected to static compressive loads. The robustness of the SMART-APPROACH was assessed in Ref. 10 taking into account only the load increment size without analysing effects of the mesh density in the damaged area. The present paper can be considered as a sequel of the Ref.10. As in Ref.10 the attention is addressed to the analysis of the behaviour of a circular delamination of known dimension and position considered as pre-existing within a structure and which growth process is assumed to take place in the original defect plane. However, here, two different objectives have been pursued: the enhancement of the SMART approach to increase the accuracy of the solution during the growth phase and the assessment of the robustness of the enhanced procedure to the element size. In what follows, firstly the SMARTapproach (Ref.10) and the algorithm proposed by Xie and Biggers in Ref.6-7 are briefly reviewed (Section 2). Then, a novel methodology named SMXB approach, obtained by combining the SMart approach and a modified Xie and Biggers [6-7] approach, is proposed (Section 3) which is able to trace, with increased accuracy, the shape of the delamination during the propagation. Finally in Section 4, the numerical results obtained by implementing the proposed methodology in ANSYS $\odot$, are compared with those obtained in Ref . 10 and with experimental results taken from literature [14].

\section{Finite element procedures based on the Virtual Crack Closure Technique for delamination growth phenomena: the SMART approach and the "Xie and Biggers" approach}

\subsection{The SMART-approach}

A strong dependency of delamination growth rate on the load step size was found by the Authors [10] when the standard Virtual Crack Closure Technique (VCCT) is applied in conjunction with a fail 
release approach in the frame of non linear analyses of stiffened panels with circular embedded delaminations under compressive loads. The underlying causes of this dependency were identified as the impossibility, by using the fail release approach, to detach a prescribed area and as the presence of corners in the delamination front. In order to avoid this dependency, a novel approach (SMART approach) was proposed. This approach is based on the evaluation of a variable load increment whose dimension is computed on the basis of the overbalance existing between the two areas $A_{N U M}$ and $A_{E S}$ (“SMART TIME” approach) defined as in Equation 1.

$$
A_{N U M}=\sum_{k=1}^{N} A_{k}^{E L} \quad A_{E S}=\sum_{k=1}^{N} A_{E S k}=\sum_{k=1}^{N}\left(\frac{F_{k I}^{(n+1)} \Delta u_{k I}^{(n+1)}}{2 G_{I C}}+\frac{F_{k I I}^{(n+1)} \Delta u_{k I I}^{(n+1)}}{2 G_{I I C}}+\frac{F_{k I I I}^{(n+1)} \Delta u_{k}^{(n+1)}}{2 G_{I I I C}}\right)
$$

In this equation $A_{k}^{E L}$ is the area of the finite element, $\mathrm{N}$ is the number of nodes on the delamination front where the Strain Energy Release Rate overcomes critical values, $\left(F_{k I}, F_{k I I}, F_{k I I}\right),\left(\Delta u_{k I}, \Delta u_{k I I}, \Delta u_{k I I}\right)$ and $\left(G_{I C}, G_{I I C}, G_{I I I C}\right)$ are respectively the components of the force $\mathrm{F}$ at the crack tip (node $k$ ), crack opening displacements and material fracture toughnesses for the three fracture modes I-peel,IIshear,III-tearing. The "SMART TIME" procedure [10] defines an adaptive relationship, between the load step increment of the non linear analysis and the element size of the finite element model in the damaged area, by means of a convergence check based on the criterion $A_{E S} \cong A_{N U M}$. The use of the "SMART-TIME" approach requires the solution to be found iteratively: for each load step, the solution is computed starting from the configuration frozen at the previous step and a load step increment is chosen as initial guess. Then the Strain Energy Release Rate components $\left(\mathrm{G}_{\mathrm{I}}, \mathrm{G}_{\mathrm{II}}\right.$ and $\left.\mathrm{G}_{\mathrm{III}}\right)$ are computed by using VCCT formulae as well as the two quantities $\mathrm{A}_{\mathrm{ES}}$ and $\mathrm{A}_{\mathrm{NUM}}$ (equation (1)). The check of the equivalence between these two areas is performed and if required the load step size is modified in agreement with the sign of the overbalance found between them (i.e. if $A_{E S}>A_{N U M}$ the load step size is reduced). The solution phase is restarted from the last converged one and this is repeated until the convergence is reached (a tolerance is defined for the satisfaction of the criterion). The SMART-approach is composed by the SMART-TIME and the SMART-CORNER approaches. The latter was introduced to take into account that, as consequence of the propagation, the 
delamination front, this is initially circular, after a few steps may assume a complex and stepped shape with corners. Thus, weight factors, determined taking into account the geometry of the damaged area, were introduced in formulae of the Virtual Crack Closure Technique to take into account of the nonsmoothness of the delamination front (SMART-CORNER).

\subsection{The Xie and Biggers approach}

The algorithm proposed by Xie and Biggers ("XB") [6-7] allows the determination of the actual shape of the delamination front to be traced with accuracy even when non-orthogonal meshes are used. This algorithm is based on the definition, for each node on the delamination front ( $\mathrm{N}$ in Figure 1), of eight vectors $\left(\mathbf{R}_{\mathbf{1}}, \ldots \mathbf{R}_{\mathbf{8}}\right)$ of which two ( $\mathbf{R e}$ and $\left.\mathbf{R b}\right)$ divide the bonded nodes from the debonded nodes. The damage state of the nodes surrounding $\mathrm{N}$ is defined by a variable, $\mathbf{m}$, which is equal to 0 if the nodes are bonded or 1 if the nodes are separated. By assuming that $m_{0=} m_{8}$ and $m_{9}=m_{1}$ the two vectors $\mathbf{R e}$ and $\mathbf{R b}$ can be defined by using the equation (2).

$$
\mathbf{R}_{b}=\sum_{i=1}^{8} m_{i-1}\left(1-m_{i}\right) \mathbf{R}_{i} ; \mathbf{R}_{e}=\sum_{i=1}^{8} m_{i+1}\left(1-m_{i}\right) \mathbf{R}_{i}
$$

Where $\mathrm{R}_{\mathrm{e}}$ (and $\mathrm{R}_{\mathrm{b}}$ ) coincides with one of the vectors $\mathrm{R}_{1} . . \mathrm{R}_{8}$ depending on the shape of the delamination front. For example, in the case shown in Fig 1 : $\mathrm{R}_{\mathrm{b}}$ overlaps the vector $\mathrm{R}_{5}$, consequently, the index " $b$ " is equal to 5 and the vectors $R_{b-1}$ and $R_{b+1}$ are respectively $R_{4}$ and $R_{6}$. In the same case, Re overlaps the vector $R_{2}$, the index " $e$ " is equal to 2 and the vectors $R_{\mathrm{e}-1}$ and $R_{\mathrm{e}+1}$ are respectively $\mathrm{R}_{1}$ and $R_{3}$. Starting from the knowledge of these vectors it is possible to define the vector normal to the delamination front at point $\mathrm{N}$. This normal vector is approximated by Xie and Biggers as the resultant of the two vectors $\mathbf{R e}$ and $\mathbf{R b}$. Then, it is possible to define the unit normal $\mathbf{n}$ and tangent $\mathbf{t}$ vectors to the delamination front (Figure 1-left). The three unit vectors $(\mathbf{n}, \mathbf{t}, \mathbf{k})$ form a base for the local coordinate system in which the components of the Strain Energy Release Rate $\left(\mathrm{G}_{\mathrm{I}}, \mathrm{G}_{\mathrm{II}}\right.$ and $\left.\mathrm{G}_{\mathrm{III}}\right)$ have to be calculated. Then, Xie and Biggers proposed an approach to calculate the virtually closed area to be used in the evaluation of the Strain Energy Release Rate with the VCCT. Within this approach, the area is subdivided in two parts $\mathrm{A}_{1}$ and $\mathrm{A}_{2}$ (Figure 1). Four points (XB points: $P_{i}^{j} \quad \mathrm{i}=1 . .4, \mathrm{j}=1 . .2$ ) defined in the natural coordinate $\operatorname{system}(\xi, \eta)$ enclose each of these areas. The coordinates of these points, 
expressed in terms of components of the vectors $\mathrm{R}_{1} . . \mathrm{R}_{8}$ (analytical expressions are available in Ref.6 and Ref. 7), can be transformed into the physical space $(x, y)$ by means of the shape function $N$ of the element. Once the points in Figure 1 are known, $\mathrm{XB}$ proposed to compute the areas $\mathrm{A}_{1}$ and $\mathrm{A}_{2}$ and than the total area A by using the Gauss quadrature. Then, the opening behind the delamination front is defined as that measured in the position anti-symmetric to points $P_{1}^{2}, P_{4}^{2}$ about $(0,0)$ in the natural reference system $(\xi, \eta)$.The displacement components for the delamination opening are obtained at the point $\mathrm{P}_{0}$ by means of the shape functions of the element.

\section{Formulation of an enhanced procedure}

The algorithm proposed by Xie and Biggers (XB) [6-7], and described in the previous section, has been modified in order to increase the accuracy of the methodology in determining the value of the area to be used in the Strain Energy Release Rate computation and in the definition of the shape of the delamination front.

\subsection{Modifications to the algorithm proposed by Xie and Biggers}

- The coordinates of the points are determined taking into account the deformed configuration of the structure at each load level of displacement controlled non-linear analyses;

- the point $P_{4}^{1}$ is determined as intersection between $\mathrm{R}_{\mathrm{e}}$ and the line orthogonal to $\mathrm{R}_{\mathrm{e}}$ passing through $P_{3}^{1}$ rather than as semi-sum of the components of the vectors " $\mathrm{R}_{e-1}$ " and " $\mathrm{R}_{e+1}$ " as proposed by Xie and Biggers [6-7]. This has been done in order to obtain a more accurate evaluation of the position of the Point $P_{4}^{1}$ when the FE element has not a rectangular shape (aspect ratio greater than 1). In the same way, the point $P_{2}^{2}$ is determined as intersection between $\mathrm{R}_{\mathrm{b}}$ and the line orthogonal to $\mathrm{R}_{\mathrm{b}}$ passing through $P_{3}^{2}$ instead of computing it as semi-sum of the components of the vectors " $\mathrm{R}_{b-1}$ " and " $\mathrm{R}_{b+1}$ ";

- Instead of using the Gauss quadrature to compute the areas $A_{1}$ and $A_{2}$ [6-7], the Shoelace formula (equation (3)) has been used. This formula allows determining exactly the area of a polygon when the coordinates of its vertex $\left(x_{i}, y_{i}\right)$ are known. 
$A_{P}=\frac{1}{2}\left|x_{1} y_{2}+x_{2} y_{3}+\ldots . .+x_{n-1} y_{n}-x_{n} y_{1}-x_{3} y_{2}-\ldots . .-x_{n} y_{n-1}-x_{1} y_{n}\right|$

When dealing with growth phenomena of circular embedded delaminations, orthogonal meshes can be used which edges are parallel or perpendicular to the initial delamination front. In this case, the delamination growth is assumed to take place in the direction normal to the initial boundary of the defect. In order to use the XB approach in conjunction with orthogonal mesh for circular delaminations, two other modifications have been introduced:

- The vectors and node positions identified in Figure 1 change as shown in Figure 2.

- In case of a corner depth (defined as ratio between the distance N-7 and the reference length LRY in Figure 2 and Figure 3) greater than 1, the positions of XB points are modified as shown in Figure 3 to avoid singularities in the evaluation of the Strain Energy Release Rate.

\subsection{Averaged Strain Energy Release Rate distributions}

When using the fail release approach to simulate the delamination growth, the minimum increment in delaminated area is determined by the area of the finite element used in the model. This means that by releasing a constraint, the delaminated area is modified according to the area of the finite element rather than to the area computed by following for example the XB algorithm. Furthermore, once a constraint is released, a corner is induced in the delamination front whose tendency is that to accumulate energy. This leads to peaks in the Strain Energy Release Rate as described in Ref.10. Thus, the real behaviour of the structure is somewhat different to the one obtained by using the fail release approach (instantaneous propagation) because during the grow phase, the energy is distributed (slow propagation) on adjacent parts thus smoothing peaks of Energy as shown in Figure 4. In order to overcome this problem, suitable interface elements that allow a slow propagation should be used instead of the fail release approach. However, in this case the problem would be moved on the definition of the damage laws to be used to define the debonding. The SMART-APPROACH proposed in Ref.10 takes into account the behaviour shown in Figure 4 by automatically adjusting the load increment on the basis of the difference between the area that should have been released $\left(\mathrm{A}_{\mathrm{ES}}\right)$ and the 
one that is effectively released $\left(\mathrm{A}_{\mathrm{NUM}}\right)$. However, Authors have detected that the effectiveness of this approach decreases as the number of corner nodes increases: this is due to the adoption of weights in the Strain Energy Release Rate computation (SMART-CORNER) which does not allow the slow propagation to be simulated. In order to find a solution to this problem the approach proposed by Shivakumar, Tan and Newman in Ref.2 has been adopted. This approach evaluates the Strain Energy Release Rate taking into account segments of delamination front rather than nodes. Furthermore, weights (computed as the ratio between the length of the segment and that of adjacent segments) are introduced in Virtual Crack Closure Technique formulae to correctly take into account the contribution of forces, evaluated at the edges of each segment, on the Strain Energy Release Rate of the segment itself. This kind of approach has been than used in conjunction with the modified XB approach (Section 3.1). Thus, the Strain Energy Release Rate in each segment $G_{I_{i}}$ of delamination front has been obtained as in Equation (4) where the index $i$ is referred to segments, the index $j$ to nodes belonging to the segment.

$$
G_{I_{i}}=\frac{1}{2 A_{i}} \sum_{j=1}^{2} F_{I_{j}}^{i} \Delta u_{I_{j}} ; F_{I_{j}}^{i}=C_{J} F_{j} ; C_{1}=\frac{A_{i}}{A_{i-1}+A_{i}} ; C_{2}=\frac{A_{i}}{A_{i+1}+A_{i}}
$$

In this equation weights $(C j)$ have been defined as ratio between the areas $A j$ obtained by using the modified XB approach (which are generally different from that of the finite element) instead of the length of the segments as proposed by Shivakumar, Tan and Newman in Ref.2.

\subsection{Integration of the modified XB approach with the SMART-TIME: the SMXB procedure}

Even if the XB algorithm, enhanced with the introduction of the average, is expected to be able to give more accurate results with respect to the SMART-APROACH, it still suffers of the dependency of the delamination growth rate on the load increment discussed in Ref.10. Therefore, the enhanced XB procedure has been integrated with the SMART-TIME approach in order to obtain a robust and effective procedure. The novel approach has been called "SMXB procedure". Basically, with respect to the SMART-APPROACH deployed in Ref. 10, only the SMART-TIME approach has been kept whereas the SMART-CORNER procedure is no more needed. A few modifications to the original 
SMART-TIME approach have been required in order to take into account the introduction of the average between adjacent segments (Section 3.2). For example, in computing the area $A_{N U M}$, the condition for releasing a constraint at a node is that the failure index for the segment to which the node belongs to is greater then or equal to 1 and that the failure index evaluated in the node itself (computed without average) is greater then or equal to 1 . For what concerns the evaluation of the area $A_{E S}$, if the failure index for a segment is greater equal to 1 , then the contribution of that segment to the area $\mathrm{A}_{\mathrm{ES}}$ is equal to $\mathrm{A}_{\mathrm{ESij}}$ (Equation 1) or to $\mathrm{A}_{\mathrm{ESij}} / 2$ (depending on the shape of the delamination front). This distinction is required in order to avoid considering the same contribution for two different segments.

\section{Assessment of the robustness of the enhanced finite element procedure}

The stiffened panel with an embedded delamination, already used as benchmark in Ref. 10, has been chosen to validate and assess the robustness of the enhanced procedure. The geometry of this panel is described in Figure 5 and Table 1 [14], the material properties are summarized in Table 2 [15-16]. Displacement controlled non-linear analyses have been performed for this panel by using the finite element models shown in Figure 6. It is worth noting that the finite element of the stiffened panel has been obtained by using the global/local technique [9], which allows the connection of differently modelled substructures by means of Multipoint constraints. Indeed, three different FE models have been considered, the one already used in Ref. 10 characterized by the same mesh densities for the local and global model (\#M1) and other two models with refined meshes only in the local area (\#M2 and \#M3).

\subsection{Strain Energy Release Rate distribution obtained by using different approaches on the same}

\section{delamination front}

Many different mixed-mode failure criteria have been suggested in the literature for predicting delamination growth [17]. These criteria are in most cases, curve fit to data from experimental tests performed to characterize the material toughness under combination of modes I,II and III. Unfortunately, when a consistent set of mixed-mode data is not available for the material of interest, it is not possible to say which criterion is the best fit of the experimental values. In these cases, the linear 
power law criterion in Eq.5 represents a good alternative being it able to introduce the mode mixities in the model without requiring the choice of fitting parameters.

$$
E d=\left(\frac{G_{I}}{G_{I C}}\right)+\left(\frac{G_{I I}}{G_{I I C}}\right)+\left(\frac{G_{I I I}}{G_{I I I C}}\right)
$$

In the equation (5), $\mathrm{G}_{\mathrm{I}}, \mathrm{G}_{\mathrm{II}}$ and $\mathrm{G}_{\mathrm{III}}$ are the components of the Strain Energy Release Rate whereas $\mathrm{G}_{\mathrm{IC}}, \mathrm{G}_{\mathrm{IIC}}$ and $\mathrm{G}_{\mathrm{IIIC}}$ are the fracture toughness.

Strain Energy Release Rate distributions obtained (local model \#M1) by using different approaches on

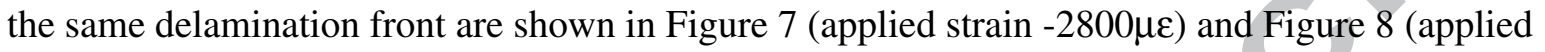
strain $-2930 \mu \varepsilon$ ). In these figures, the approach based on the standard application of the VCCT has been labelled as "Classic approach", the procedure proposed by Xie and Biggers [6-7] is referred as "XB Original approach" whereas the enhanced XB approach (Section 3) is called "XB Enhanced approach". No significant differences in terms of failure index Ed [17] (Equation 5) have been found when the Strain Energy Release Rate is computed on a delamination front without corners. When the delamination front is characterized by the presence of corners, the introduction of the average between adjacent segments leads to a smoothed distribution of Strain Energy Release Rate and consequently of the failure index Ed. It is worth emphasizing that the introduction of the average effectively allows "in some ways" the slow propagation to be simulated as it can be seen by comparing Figure 7 and Figure 8 and the sketch reported in Figure 4.

\subsection{Comparison between numerical and experimental results}

The SMXB has been used in conjunction with the global/local technique in order to analyze the sensitivity of the solution to the mesh density in the delaminated area keeping reasonable the computational efforts. Three analyses have been performed by using respectively the three local finite element models shown in Figure 6. It is worth noting that the SMART-APPROACH was used in Ref. 10 in conjunction with the local model \#M1. Results have been compared in terms of global behaviour of the panel and delamination growth rate and delaminated area. From a damage criticality prospective, the delamination extent can be considered as a more relevant parameter then the 
delaminated area to measure how well the models fitted the experiments, especially when modelling the delamination in a stiffened panel. However, since the purpose of using three different FE-models was to investigate the sensitivity of the solution to the mesh density or equivalently to the element size, the delaminated area has been chosen instead of the delamination extent for comparing numerical results and consequently also to assess their agreement with experimental data. Figure 9 and Figure 10 show the out of plane contour plot of the stiffened panel at above $-4000 \mu \varepsilon$. The delaminated shape has been made visible by deactivating the MPCs that have been released (in ANSYS this operation is possible by visualizing only "live" elements [18]). It is worth noting that the deformed configurations obtained by using the three different local models (Figure 10) are very similar both in terms of buckling shape and of minimum $(-3.3 \mathrm{~mm})$ and maximum values of the out of plane displacements $(3.9 \mathrm{~mm})$. Indeed, the results of the analyses have been compared quantitatively in terms of out-of plane displacement versus applied strain graph of the node placed in the middle of the delaminated area (point $U$ ) as shown in Figure 11. The results obtained by using the SMXB approach are in very good agreement with that obtained by using the SMART approach, furthermore the global $(-2700 \mu \varepsilon)$ and the local buckling load $(-1100 \mu \varepsilon)$ are very close to the experimental results (global and local buckling load respectively equal to $-2850 \mu \varepsilon$ and $-1250 \mu \varepsilon$ ). A good agreement has been also obtained in terms of End-shortening versus applied strain graph as shown in Figure 12. Indeed, this agreement demonstrates the robustness of the enhanced procedure to the mesh density but also that the global/local technique is very effective in performing this kind of analysis. The delaminated shapes obtained at above $-3700 \mu \varepsilon$ by using the two numerical approaches (SMART and SMXB) have been compared with the experimental C-SCAN [14] as shown in Figure 13. Delaminated areas obtained by using the SMXB approach (local model \#M3) at different values of the applied displacement are shown in Figure 14. The agreement between the numerical predictions and the experimental results (Figure 13) is clearly visible especially on the left hand side lobe of the delamination. Indeed, as demonstrated in Ref. 19 by using fractography, the different extension of the delaminated area on the right and left hand side is due to the delamination migrating towards free surface on the left hand side 
and migrating deeper into the laminate on the right hand side. The model developed is able to simulate a delamination growth within the original defect plane neglecting this effect. However, it is worth noting that by increasing the applied strain from $-3700 \mu \varepsilon$ to $-4100 \mu \varepsilon$ the delaminated area grows in agreement with the Experimental C-Scan image. The delamination growth rates obtained are shown in Figure 15. The agreement between numerical and experimental results demonstrates the effectiveness of the numerical models in predicting the damage evolution whichever the mesh density is, for low strains. For higher strains, the comparison between numerical and experimental data is affected by the simplified hypothesis made on the plane where the delamination can growth.

\section{Conclusions}

The procedure proposed by the Authors in Ref.10 (SMART-APPROACH) has been enhanced with an algorithm for tracing with accuracy the shape of the delaminated front during the propagation phase and for simulating a slow propagation instead of an instantaneous propagation when a constraint is released in the frame of the fail release approach. This enhanced procedure (SMXB-APPROACH) has been implemented in ANSYS (C) APDL and it has been used to analyse the behaviour of a stiffened panel with an embedded circular delamination under compressive load already analysed in Ref.10. With the aim to perform a sensitivity analysis of the results to the element size in the delaminated area, a global/local technique has been used in order to be able to modify the mesh density in the damaged area keeping coarse that of the undamaged part of the panel. Three different FE local models have been considered, the one already used in Ref. 10 characterized by the same mesh densities for the local and global model (\#M1) and other two models with refined meshes in the local area (\#M2 and \#M3). Results have been compared in terms of both local behaviour (shape of the delaminated area, delamination growth rate) and global behaviour of the panel. The very good agreement found between numerical results (all models) demonstrates the robustness of the SMXB-APPROACH to mesh density and load increment for delamination growth phenomena. Furthermore, it has been observed that, with respect to the SMART-APPROACH, the SMXB is able to follow with more accuracy the experimental results whichever the mesh density of the local area is. The effectiveness of the procedure developed is proved by the close agreement between numerical and experimental results for 
low strains. For higher strains, the models underestimate the experimentally observed [19]

unsymmetrical growth of the debonded area, which is more pronounced on the left hand side lobe.

Indeed, as demonstrated in Ref.19 by using fractography, this unsymmetrical growth of the delamination is due to a delamination migration in adjacent plies, phenomenon that the models developed do not take into account. As future development of the proposed methodology, a procedure for taking into account multi-plane growth is worth investigating as well as the possibility to use nonorthogonal meshes.

\section{Acknowledgements}

The research leading to these results has received funding from the European Community's Seventh Framework Programme FP7/2007-2013 under grant agreement n²13371-MAAXIMUS (www.maaximus.eu.).

\section{References}

[1] Raju I.S., Calculation of strain-Strain Energy Release Rates with higher order an singular finite elements, Engineering Fracture Mechanics, 1987, 28, 251-274

[2] Shivakumar K.N., Tan P.W., Newman J.C. Jr, A virtual crack closure technique for calculating stress intensity factors for cracked three dimensional bodies, International Journal of Fracture, 1988, 36, R43-R50

[3] Rybicki E.F., Kanninen M.F., A finite element calculation of stress intensity factors by a modified crack closure integral, Engineering Fracture Mechanics, 1997, 9, 931-938

[4] Krueger R., The Virtual Crack Closure Technique: History, Approach and Applications, NASA/CR-2002-211628.

[5] Mabson G.E., Deobald L.R., Dopker B.,.Hoyt D.M, Baylor J.S., Graesser D.L.. Fracture interface elements for static and fatigue analysis. 16th international conference on composite materials. ICCM16, Kyoto, Japan, 2007

[6] De Xie,Sherrill B. Biggers, Strain Strain Energy Release Rate calculation for a moving delamination front of arbitrary shape based on the virtual crack closure technique. Part I: Formulation and validation. Engineering fracture mechanics 2006, 73(6), 771-785.

[7] De Xie, Sherrill B. Biggers. Strain Strain Energy Release Rate calculation for a moving delamination front of arbitrary shape based on the virtual crack closure technique. Part II: Sensitivity study on modeling details, Engineering fracture mechanics 2006, 73(6), 786-801.

[8] Orifici A.C., Thomson R.S., Degenhardt R., Bisagni C.and Bayandor J., Development of a finiteelement analysis methodology for the propagation of delaminations in Composite structures, Mechanics of composite Materials, Vol.43, No.1, 2007

[9] Pietropaoli E., Riccio A. A global/local finite element approach for predicting interlaminar and intralaminar damage evolution in composite stiffened panels under compressive load. Applied Composite Materials, 2010 (DOI 10.1007/s10443-010-9135-1). 
[10] Pietropaoli E., Riccio A., "On the robustness of finite element procedures based on Virtual Crack Closure Technique and fail release approach for delamination growth phenomena. Definition and assessment of a novel methodology" Composites Science and Technology 70 (2010) 1288-13003.

[11] Ferrie C. H. and Rousseau C.Q, A Method of Applying VCCT to Corner Crack Nodes, Proceedings of the American Society for Composites - 16th Annual Technical Conference on Composite Materials, Blacksburg, Va., USA, 2001

[12]Krueger R., Goetze D., Influence of finite element software on Strain Energy Release Rates computed using the virtual crack closure technique, NASA/CR-2006-214523.

[13] Krueger R. An approach to assess delamination propagation simulation capabilities in commercial finite element codes, NASA TM/2008-215123.

[14] Greenhalgh E., Meeks C., Clarke A., Thatcher J., The effect of defects on the performance of post-buckled CFRP stringer-stiffened panels, Composites: Part A 34,2003, 623-633.

[15] Asp L., Sjogren A., Greenhalgh E., Delamination growth and thresholds in a carbon/epoxy composite under fatigue loading, Journal Compos Technol Res, 23, 55-68,2001

[16] Tsamtsakis D., Wevers M., De Meester P., Damage monitoring during fatigue loading of quasiisotropic carbon epoxy laminates, Non destructive testing Van Hemelrijck \& Annastassopulos eds, 1996 Balken Rotterdam, ISBN 905410595X

[17] Reeder J.R, An evaluation of mixed-mode delamination failure criteria, NASA-TM-104210.

[18]ANSYS 12 User Manual.

[19] Greenhalgh E.S., Rogers C., Robinson P.,Fractographic observations on delamination growth and the subsequent migration through the laminate, Composites Science and Technology 69 (2009) 23452351 . 
Figure 1: Definition of the characteristic points and of the areas that they enclosed [6-7]

Figure 2: $\mathrm{XB}$ points and coordinate systems for the node $\mathrm{N}$ (position $\mathrm{V}$ ) in the case $\mathrm{Re}=1, \mathrm{Rb}=5$

Figure 3: $\mathrm{XB}$ points for a node $\mathrm{N}$ with a depth greater than 1. On the left, the positions of the $\mathrm{XB}$ points defined as prescribed by the Xie and Biggers algorithm. The modified positions determined by the enhanced approach are shown on the right.

Figure 4: Sketch of the failure index distribution obtainable by using the fail release approach (instantaneous propagation) and by an approach that allows a slow propagation

Figure 5 Sketch of the stiffened panel with an embedded delamination, load and boundary conditions. Values of the geometrical dimensions are reported in Table 1.

Figure 6: Global FE model of the panel (left), zoomed views of local models \#M1-\#M3 (right)

Figure 7: Failure index distributions (range $-40<\theta<40$ ) obtained for an applied strain of $-2800 \mu \varepsilon$ (comparison between averaged and not-averaged results)

Figure 8: Failure index distributions (range $-40<\theta<40$ ) obtained for an for an applied strain of $-2930 \mu \varepsilon$ (comparison between averaged and not-averaged results)

Figure 9: Out of plane displacement contour plot of the stiffened panel at $-4000 \mu \varepsilon$. The local model is the \#M3 (COARSE-FINE). The delaminated shape has been made visible by deactivating the MPCs that have been released.

Figure 10: Zoomed views of the out of plane displacement contour plots of the stiffened panel at above $4000 \mu \varepsilon$ obtained by using the three local models.

Figure 11: Out of plane displacement of the point U versus applied strain graph.

Figure 12: Load (Fy) versus applied strain graph. Comparison between results of the SMART approach (\#M1 local model) and of the SMXB approach (\#M1 to \#M3 local models)

Figure 13: Comparison between the delaminated areas obtained by using the SMART-APPROACH [10], the SMXB approach and the experimental C-SCAN picture [14]. The applied strain is above $-3700 \mu \varepsilon$ 
Figure 14: Delaminated areas obtained by using the SMXB approach at different values of the applied displacement.

Figure 15: Delamination growth rate: comparison between the experimental data and the numerical results obtained by using the SMART-APPROACH (\#M1 local model) and the SMXB approach (\#M1 to \#M3 local models). 

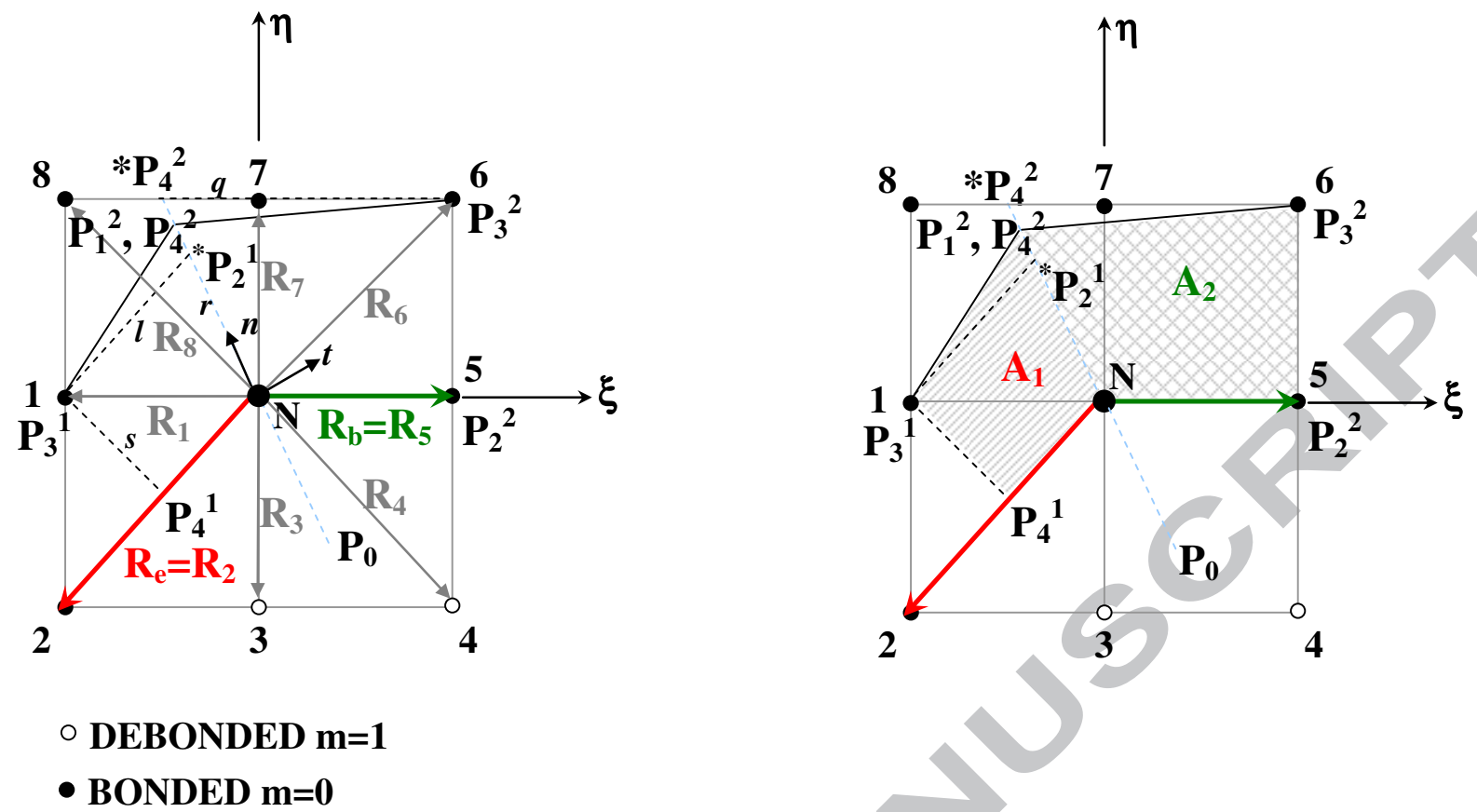

igure 1 

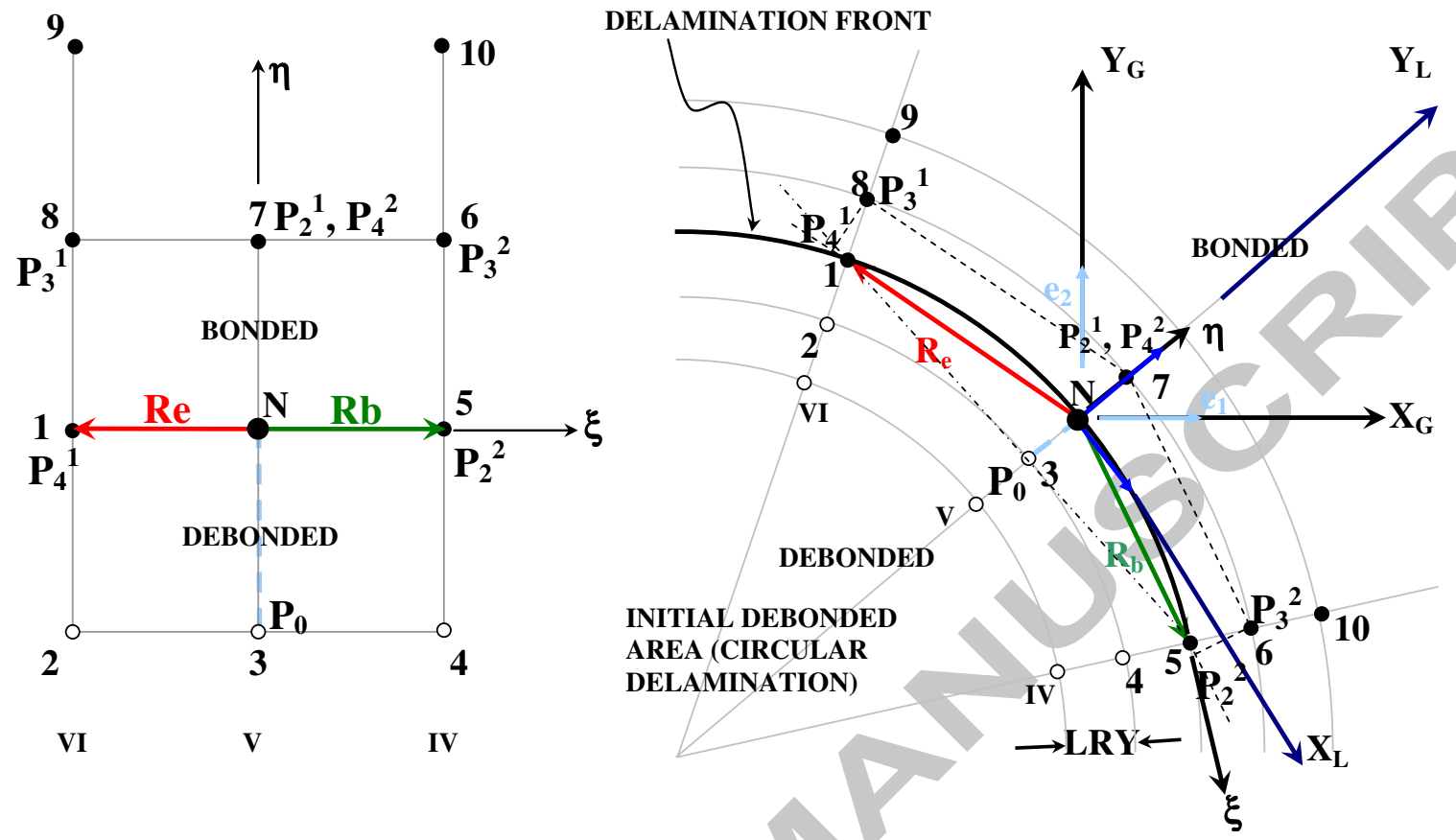

Figure 2 

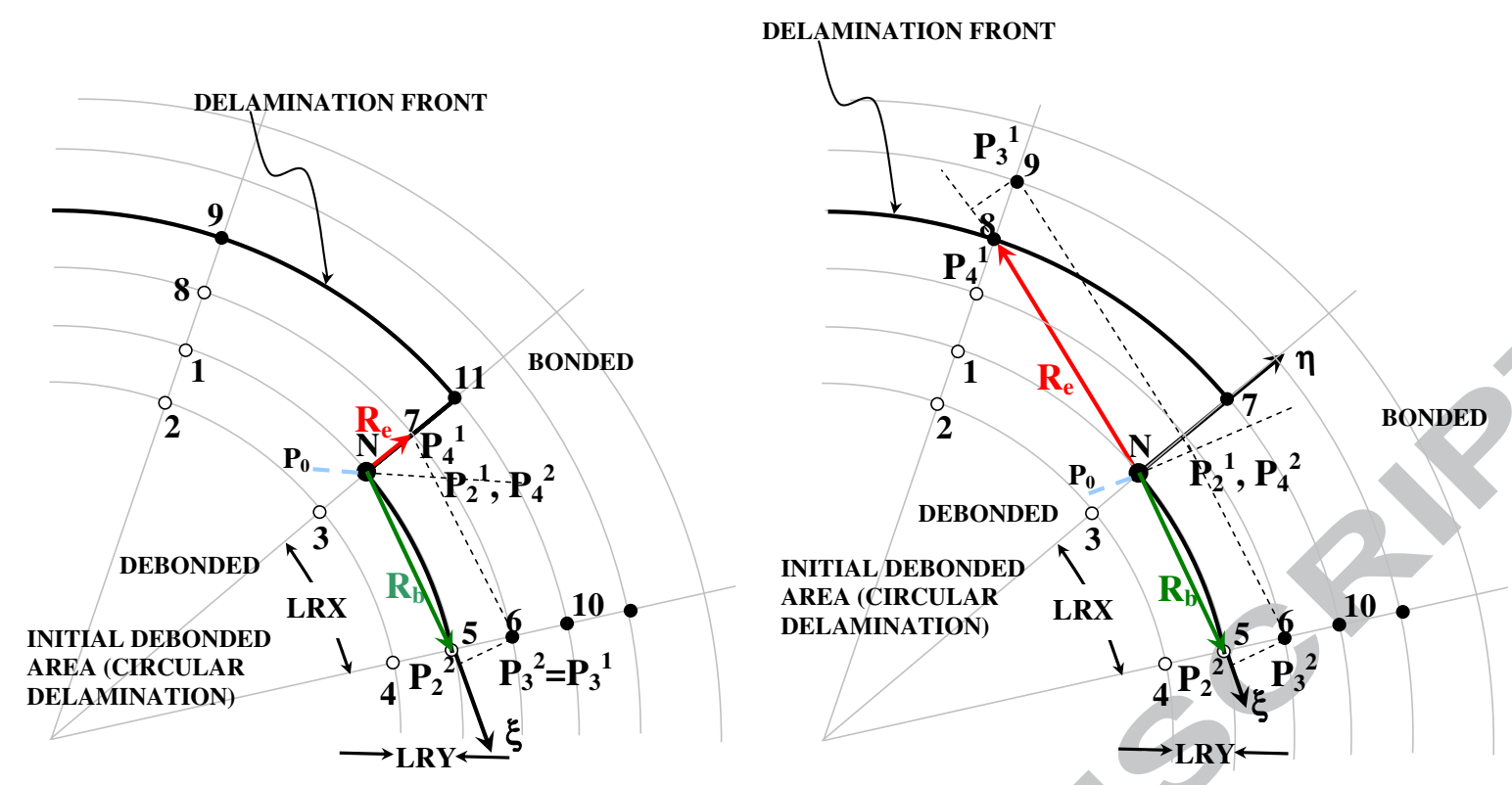

Figure 3 


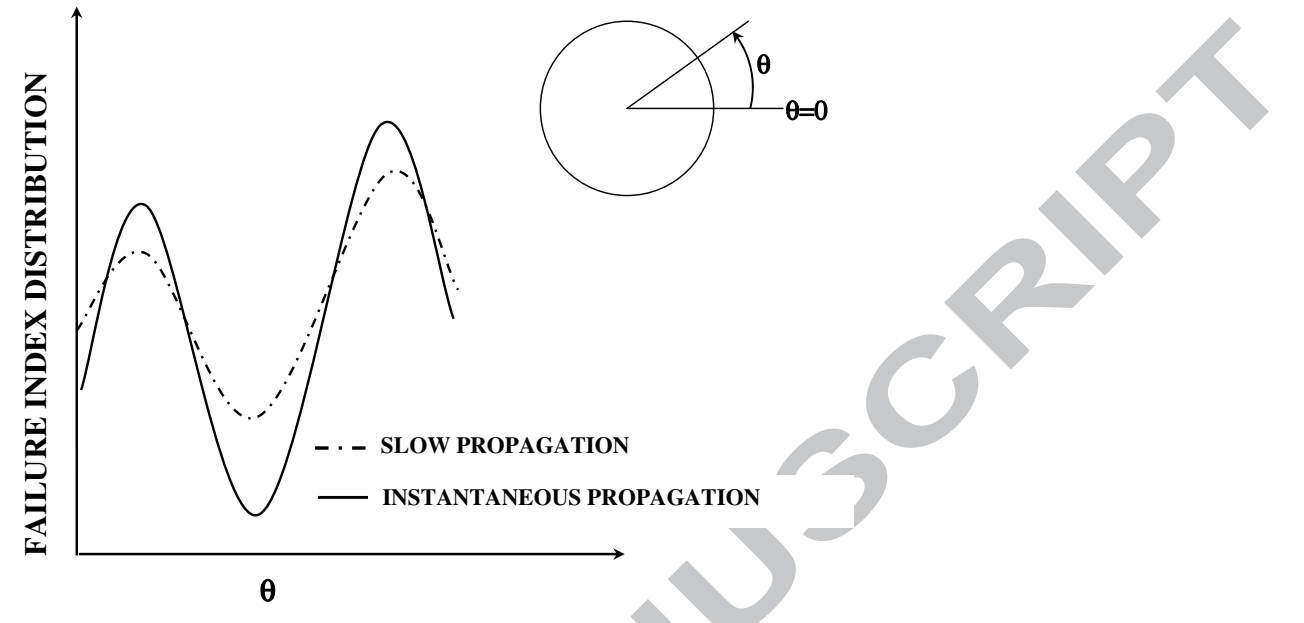

Figure 4 
SKIN: $\quad\left[+45^{\circ} /-45^{\circ} / 0^{\circ} / 90^{\circ}\right]_{3 \mathrm{~S}}$

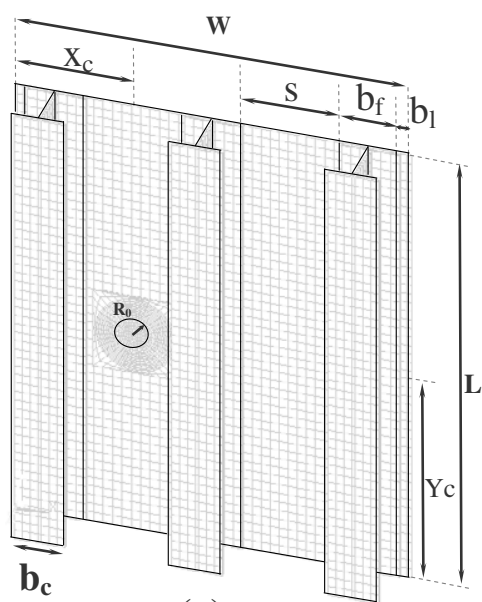

(a)

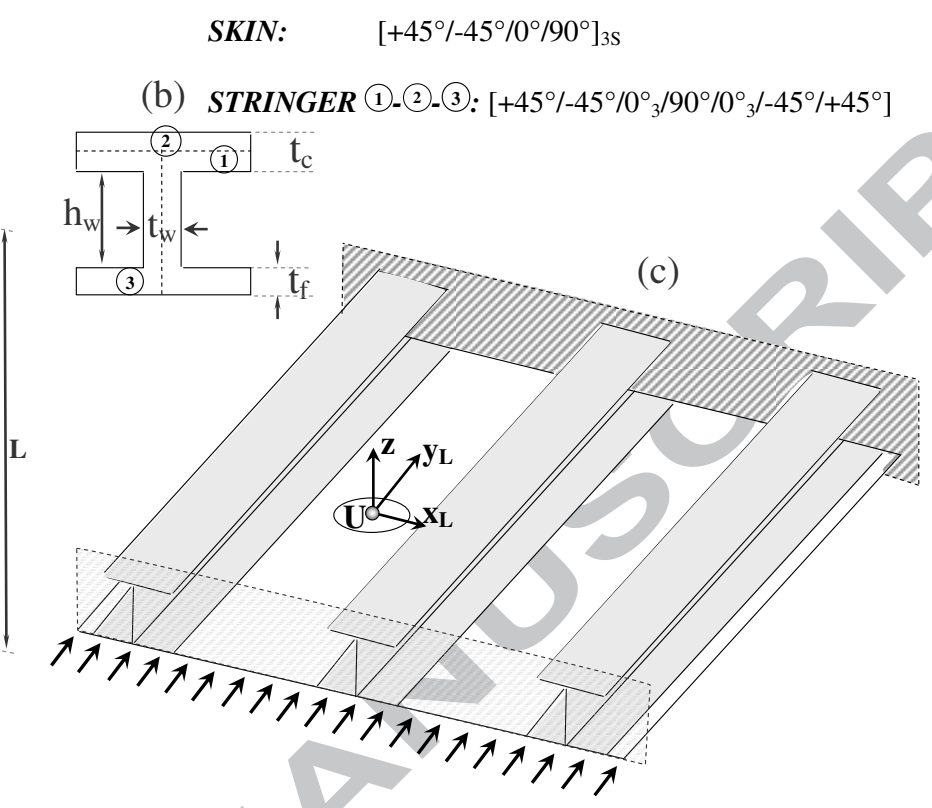

Figure 5 


\section{ACCEPTED MANUSCRIPT}

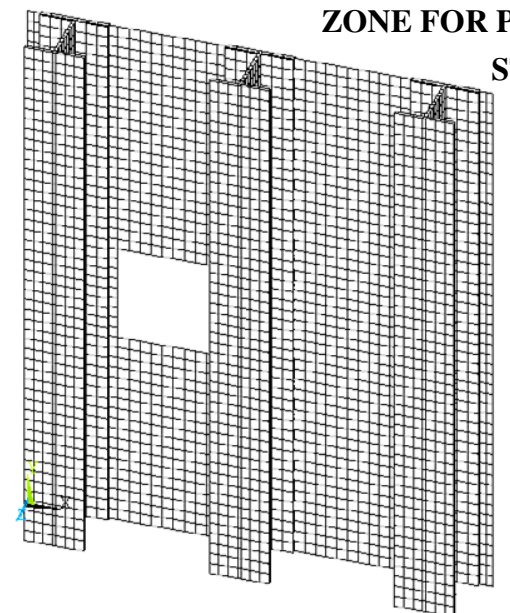

GLOBAL MODEL: COARSE

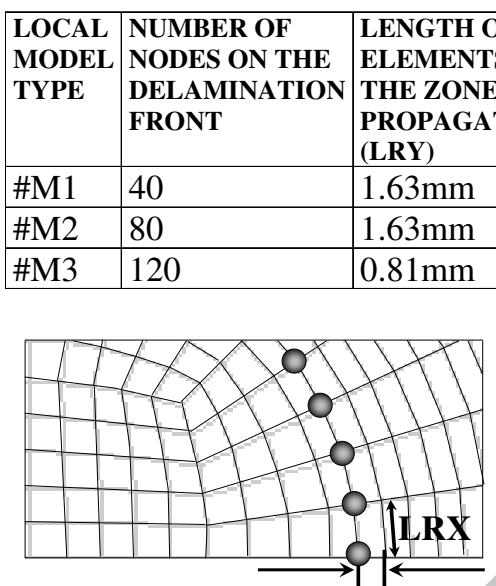

LRY

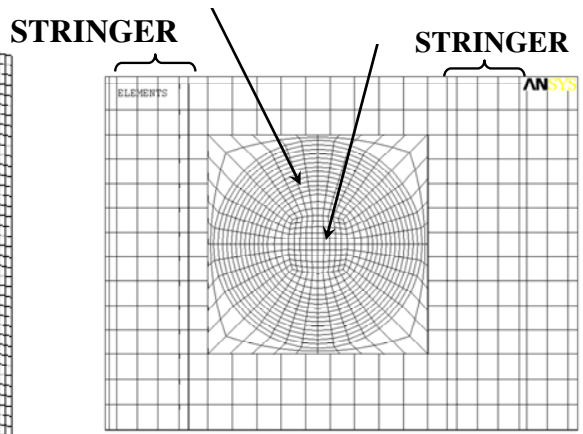

\#M1 MODEL

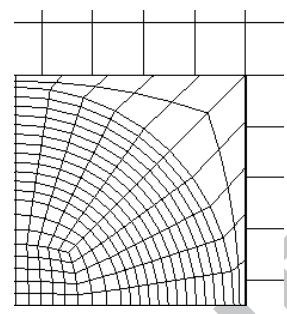

\#M2 MODEL
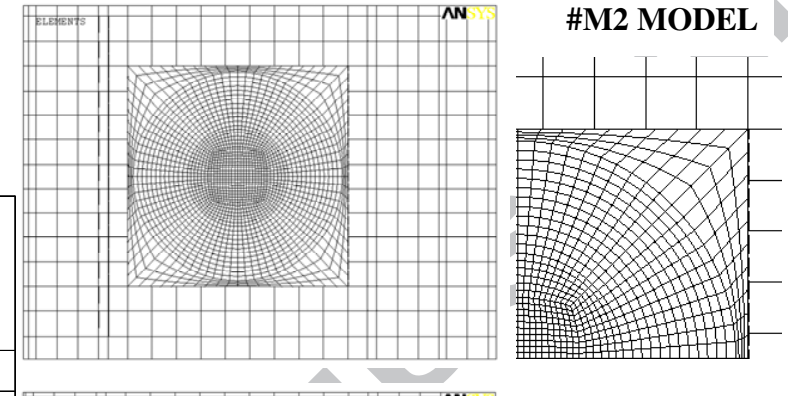

\#M3 MODEL

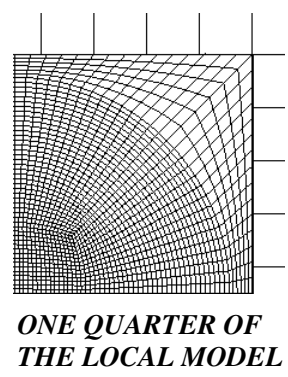

Figure 6 


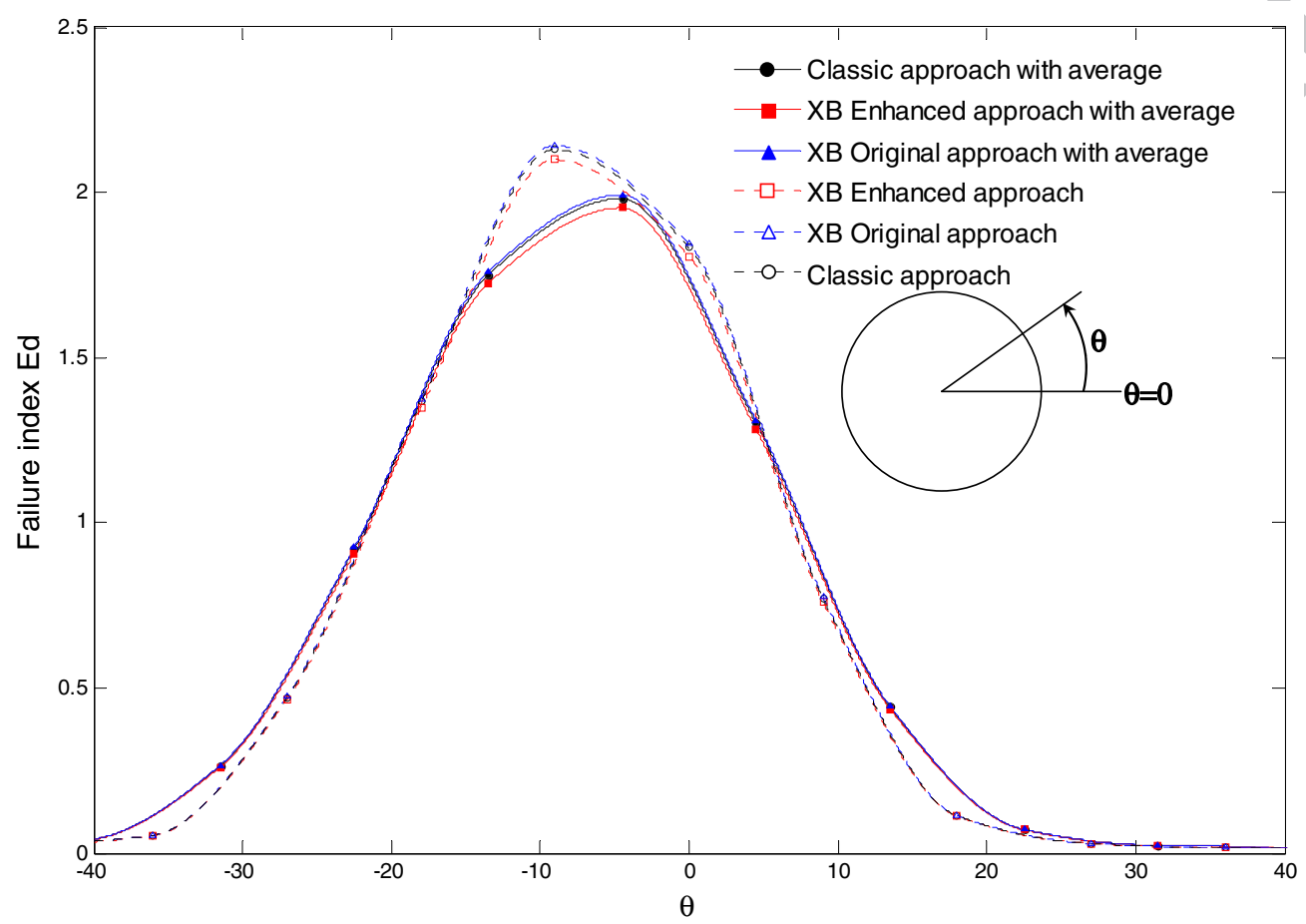

Figure 7 


\section{ACCEPTED MANUSCRIPT}

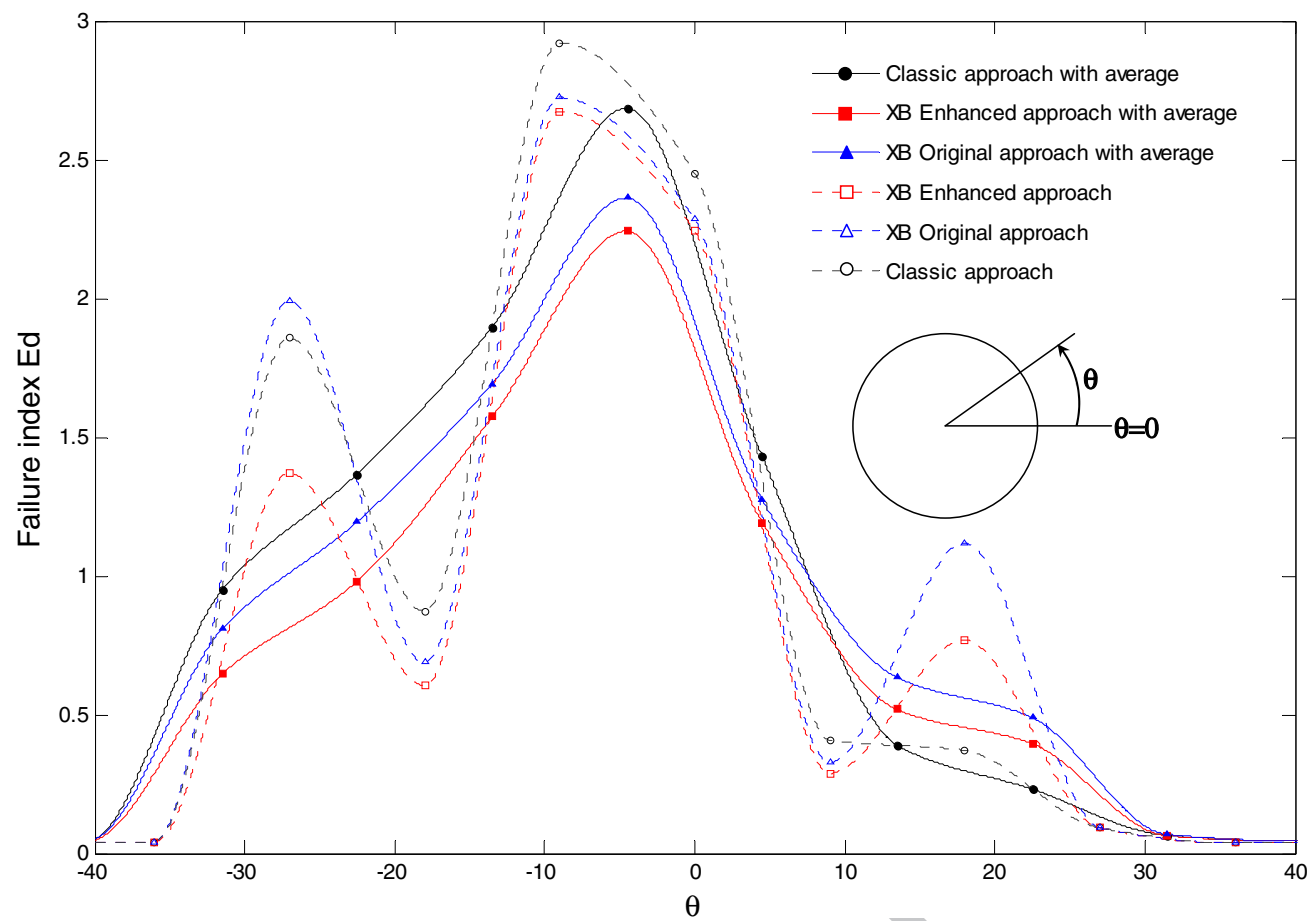

Figure 8 

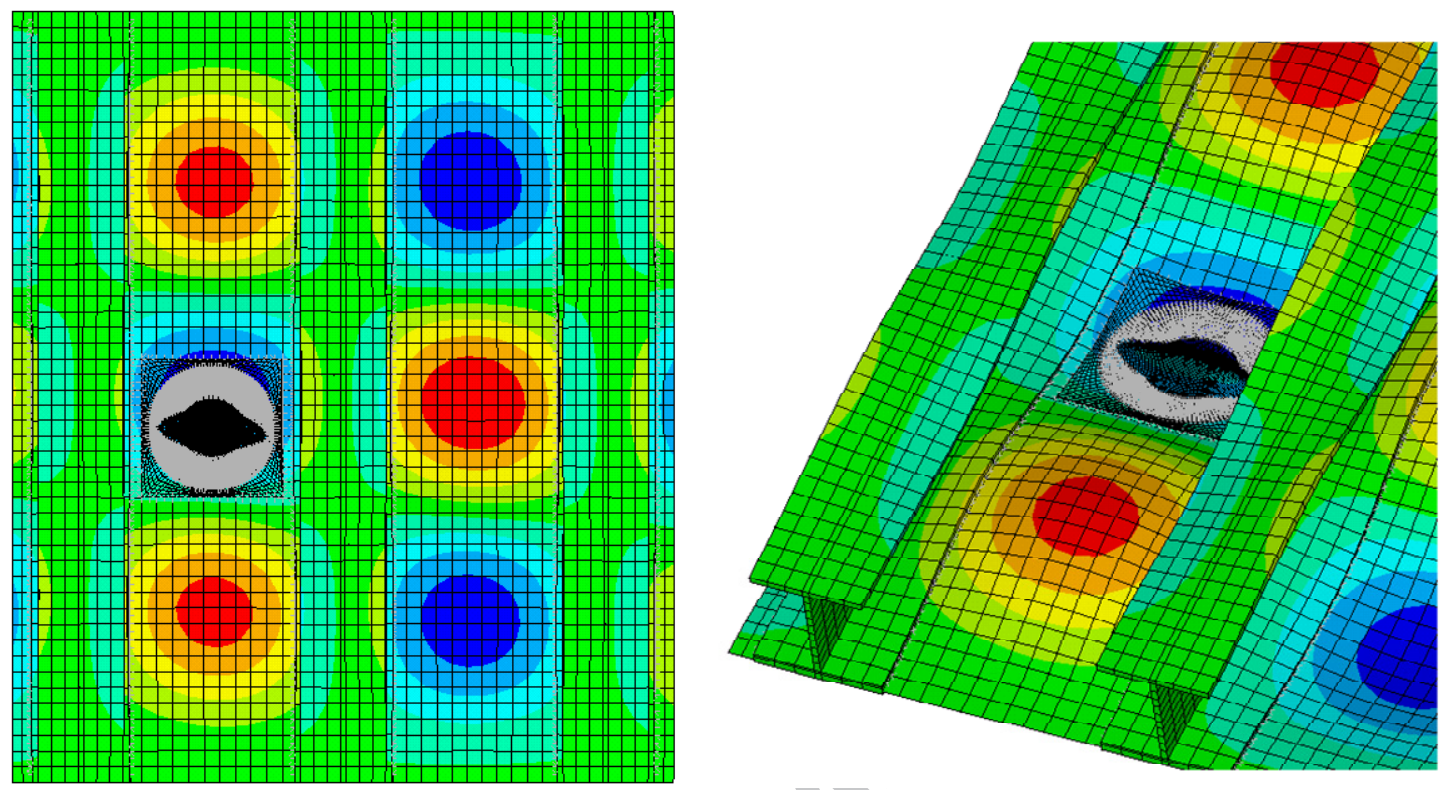

ANSYS 12.0 .1

NODAL SOLUTION

$\operatorname{STEP}=48$

$\mathrm{SUB}=1$

TIME $=48$

IT $\quad-3.325(\mathrm{DV})$

-3.325
-2.517

$-1.709$

$-.900615$

$-.092449$

.715716

1.524

2.332

3.14

3.948

Figure 9 


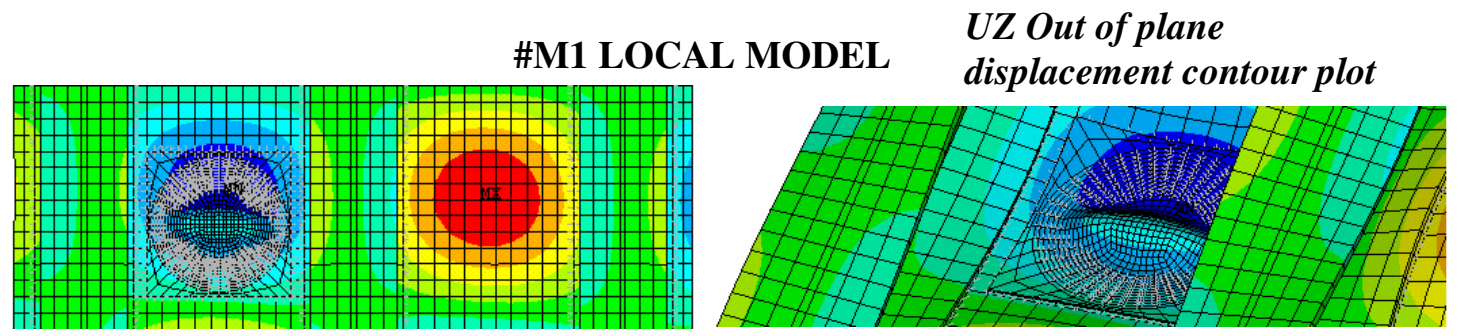

\#M2 LOCAL MODEL

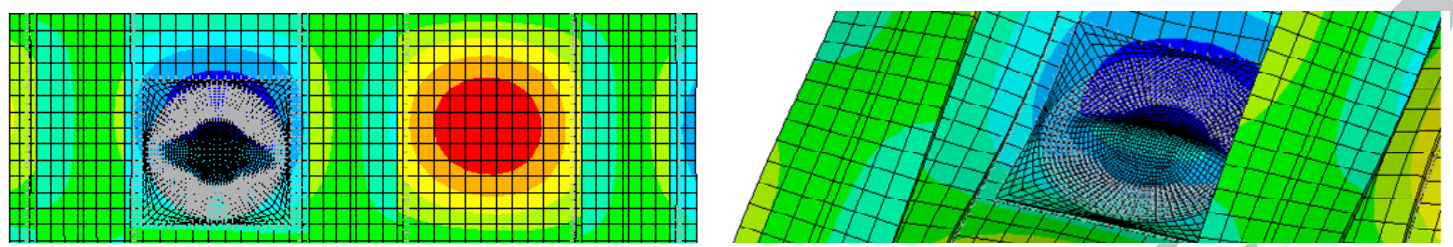

\#M3 LOCAL MODEL
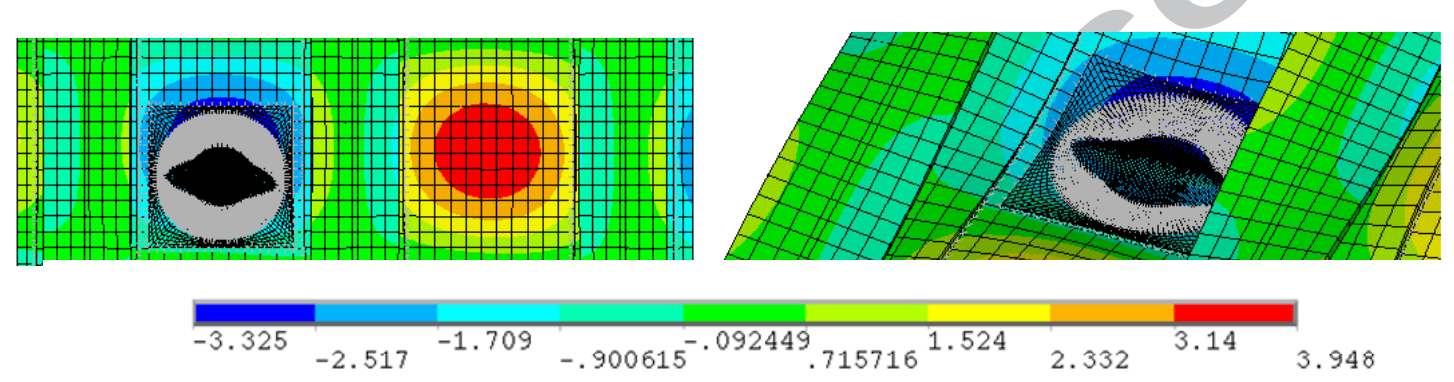

Figure 10 


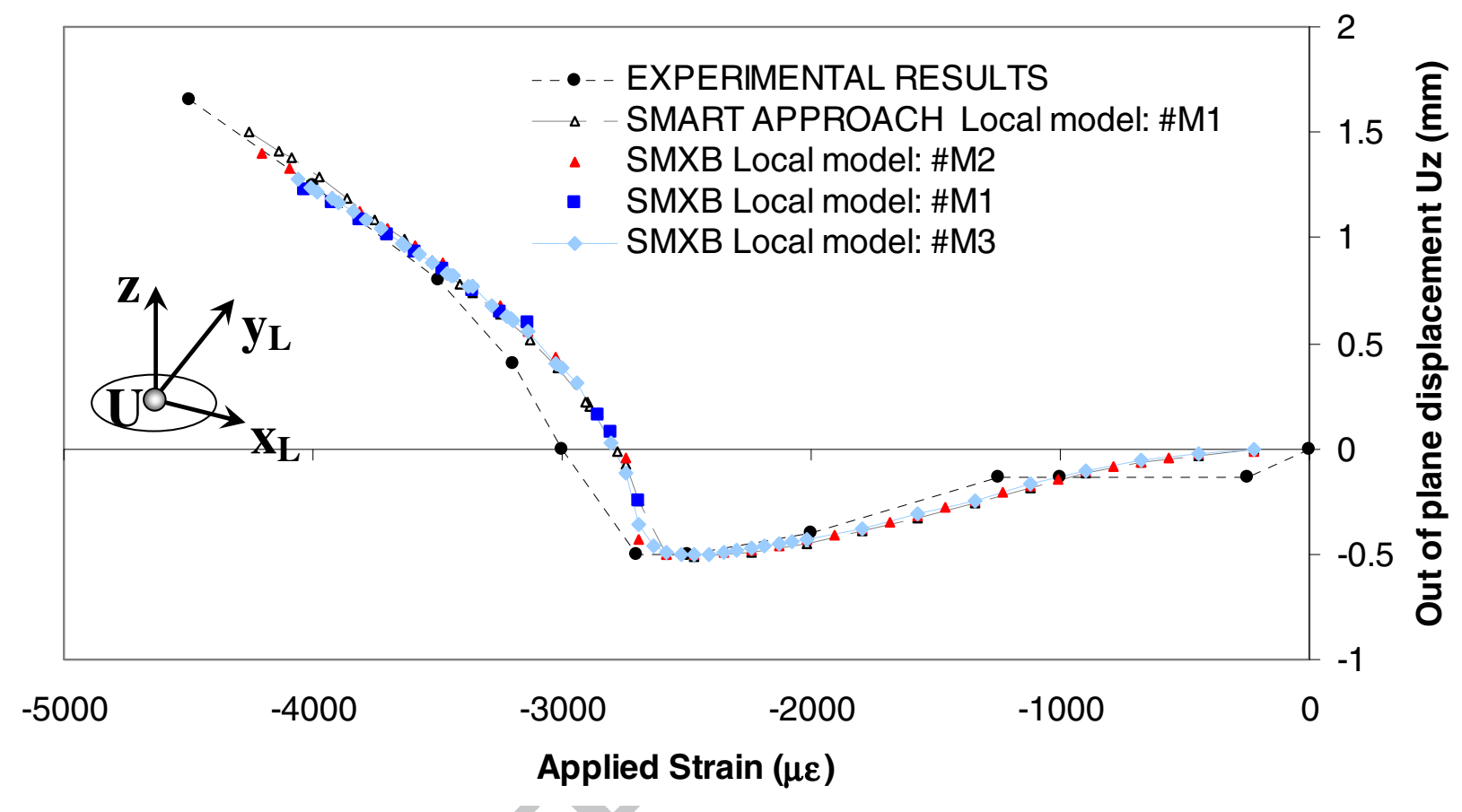

Figure 11 


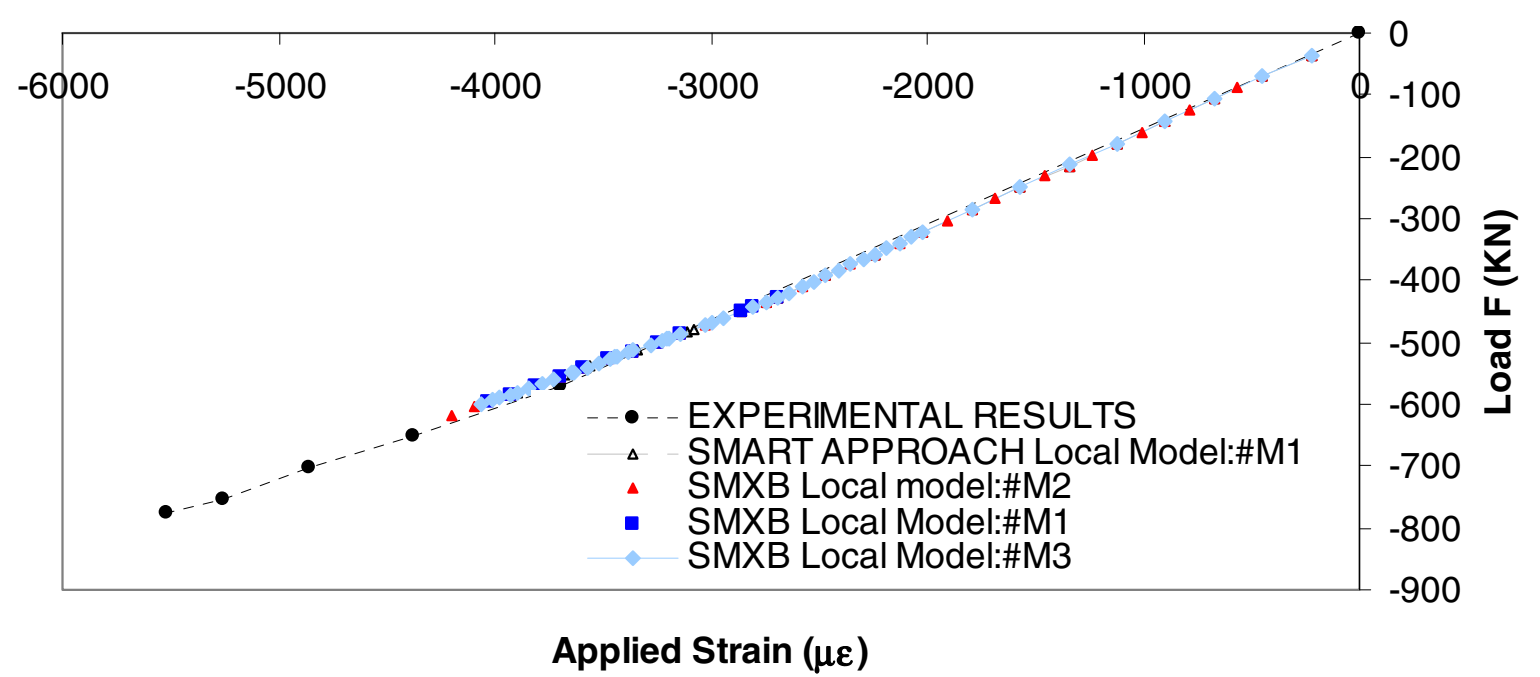

Figure 12 
SMART APPROACH

\#M1 local model, $-3700 \mu \varepsilon$

(white line)

콜
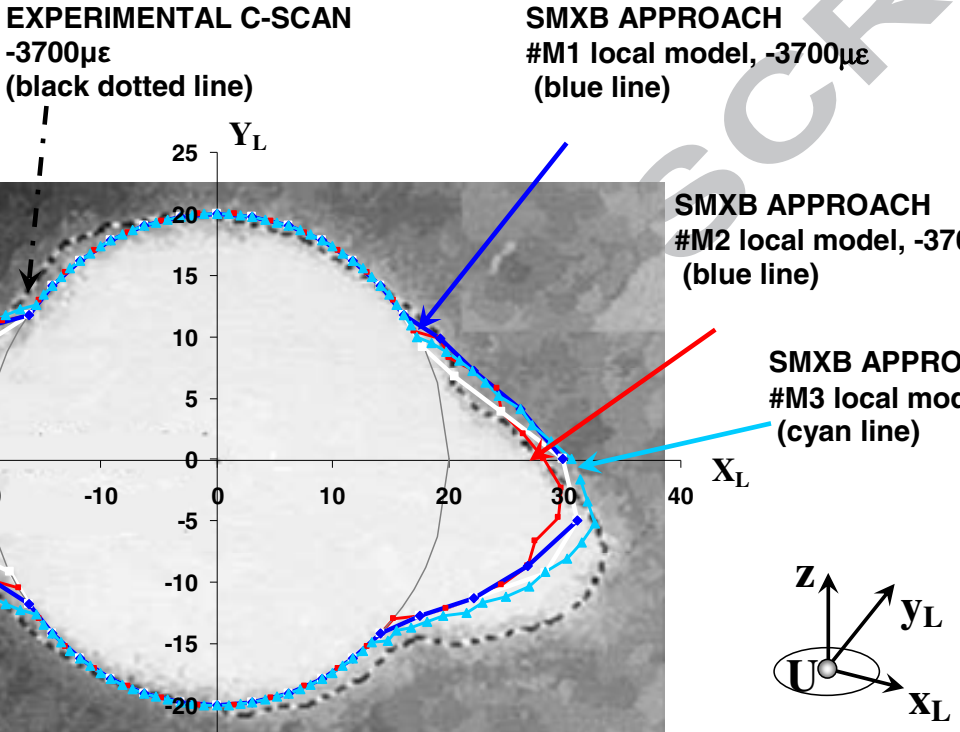

SIZE IN THE XL DIRECTION (mm)

Figure 13 


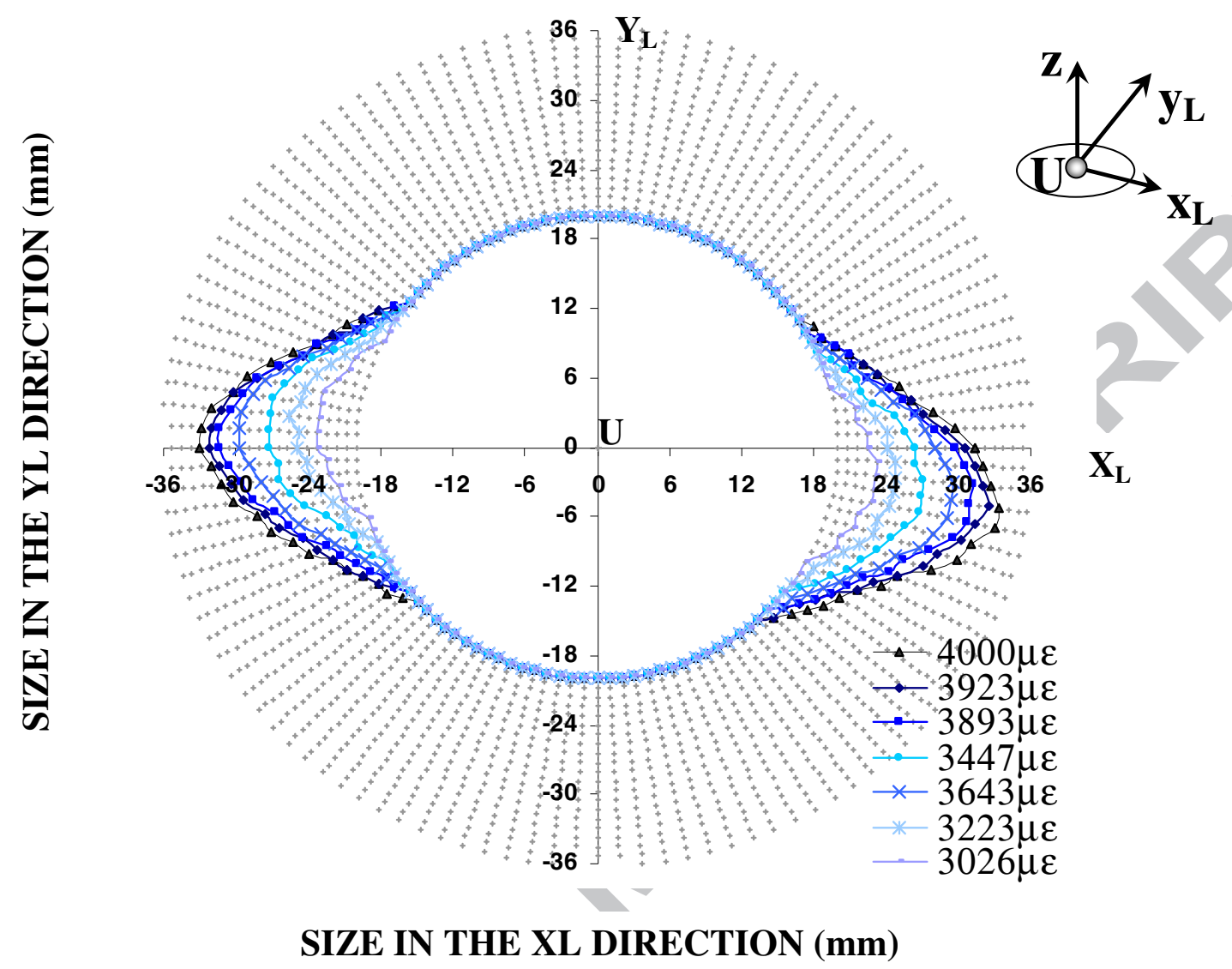

Figure 14 


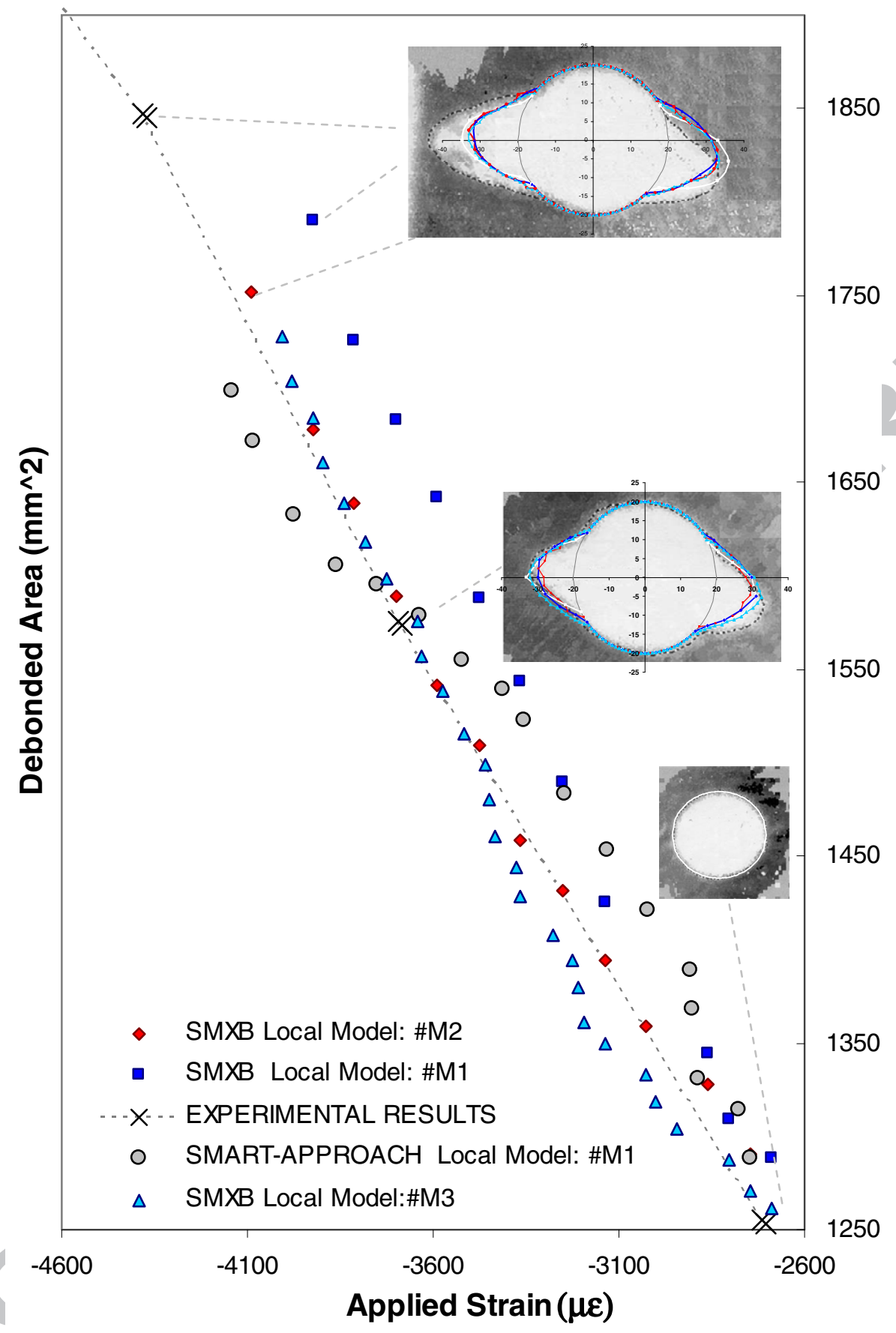

Figure 15 
table 1: Geometrical dimensions (Ref.14)

\begin{tabular}{|c|c|c|c|}
\hline $\begin{array}{l}\text { B1 (distance between the side edge and the } \\
\text { stringer foot) }\end{array}$ & $9.5 \mathrm{~mm}$ & $\mathrm{~Tb}$ (Thickness of the skin) & $3.33 \mathrm{~mm}$ \\
\hline $\mathrm{Bf}$ (width of the stringer foot) & $55 \mathrm{~mm}$ & Tf (Thickness of the stringer foot) & $1.16 \mathrm{~mm}$ \\
\hline $\mathrm{Bc}$ (width of the stringer cap) & $48.2 \mathrm{~mm}$ & Tc (Thickness of the stringer cap) & $2.80 \mathrm{~mm}$ \\
\hline $\mathrm{S}$ (distance between stringer feet) & $149 \mathrm{~mm}$ & Tw (Thickness of the stringer web) & $2.47 \mathrm{~mm}$ \\
\hline $\mathrm{R}_{0}$ (delamination radius) & $20 \mathrm{~mm}$ & Hw (Height of the stringer web) & $45 \mathrm{~mm}$ \\
\hline W (width of the panel) & $375 \mathrm{~mm}$ & $\begin{array}{l}\mathrm{X}_{\mathrm{C}} \text { (position of the middle of the } \\
\text { delamination along the width) }\end{array}$ & $113 \mathrm{~mm}$ \\
\hline $\mathrm{L}$ (length of the panel) & $446 \mathrm{~mm}$ & $\begin{array}{l}Y_{C} \text { (position of the middle of the } \\
\text { delamination along the lenght) }\end{array}$ & $205 \mathrm{~mm}$ \\
\hline
\end{tabular}


table 2: Material properties (HTA-6376C) (Ref.15 and Ref.16)

\begin{tabular}{lclc}
\hline Longitudinal tensile modulus & $140 \mathrm{GPa}$ & Longitudinal tensile strength & $2100 \mathrm{MPa}$ \\
Transverse tensile modulus & $10.5 \mathrm{GPa}$ & Transverse tensile strength & $70 \mathrm{MPa}$ \\
Poisson ratio 12 and 13 & 0.3 & Longitudinal compressive strength & $1650 \mathrm{MPa}$ \\
Poisson ratio 23 & 0.51 & Transverse compressive strength & $240 \mathrm{MPa}$ \\
In plane shear modulus 12-13 & $5.2 \mathrm{GPa}$ & In plane shear strength & $105 \mathrm{MPa}$ \\
& & & $260 \mathrm{~J} / \mathrm{m}^{2}$ \\
In plane shear modulus 2-3 & $3.48 \mathrm{GPa}$ & Critical ERR - Mode I & $950 \mathrm{~J} / \mathrm{m}^{2}$ \\
& & Critical ERR - Mode II & $1200 \mathrm{~J} / \mathrm{m}^{2}$ \\
\hline \hline
\end{tabular}

